\title{
Methodological considerations concerning the development of oral dental erosion indexes: literature survey, validity and reliability
}

\author{
Gabriele Berg-Beckhoff • Marcus Kutschmann • \\ Doris Bardehle
}

Received: 28 June 2007 / Accepted: 18 December 2007 / Published online: 29 January 2008

(C) Springer-Verlag 2007

\begin{abstract}
Within the context of preventing non-communicable diseases, the World Health Report (2002) and the WHO Global Oral Health Program (2003) put forward a new strategy of disease prevention and health promotion. Greater emphasis is placed on developing global policies in oral health promotion and oral disease prevention. The Decayed, Missing, Filled Teeth (DMFT) index does not meet new challenges in the field of oral health. Dental erosion seems to be a growing problem, and in some countries, an increase in erosion of teeth is associated with an increase in the consumption of beverages containing acids. Therefore, within a revision of the WHO Oral Health Surveys Basic Methods, new oral disease patterns, e.g. dental erosion, have to be taken into account. Within the last 20 years, many studies on dental erosion have been carried out and published. There has been a rapid growth in the number of indexes quantifying dental erosion process in different age groups. However, these indexes are not comparable. This article discusses quality criteria which an index intended for assessing tooth erosion should possess.
\end{abstract}

Keywords Tooth erosion · Gold standard · Index · Validity . Reliability

\section{Introduction}

Within the context of preventing non-communicable diseases, the World Health Report (2002) and the WHO

We declare that we have no conflict of interest.

G. Berg-Beckhoff $(\bowtie) \cdot$ M. Kutschmann $\cdot$ D. Bardehle Faculty of Public Health, Dept Epidemiology \& International Public Health, University of Bielefeld, POB 1001 31, 33501 Bielefeld, Germany

e-mail: gabriele.berg@uni-bielefeld.de
Global Oral Health Program (2003) put forward a new strategy of disease prevention and health promotion [52]. The main orientation of the WHO Oral Health Program (2003) is that oral health is integral, essential and interrelated to general health and a determinant factor for quality of life. Proper oral health care reduce the burden of disease as well as premature mortality. Risk factors for oral diseases are common with cardiovascular diseases, diabetes, cancer and chronic obstructive pulmonary diseases.

The actual WHO Global Oral Health Program focuses on priority action areas as: "Diet, nutrition and oral health", "Oral health and fluorides", "Tobacco and oral health", "School children", "Elderly people" and "Oral health services". Nutrition affects oral health in many ways, e.g. dental erosion. To minimize the occurrence of dental erosion which is particularly related to acidic beverages, the WHO/FAO (Food and Agricultural Organization of the $\mathrm{UN}$ ) recommends (within their recently published Global Strategy on Diet, Physical Activity and Health) a reduction in the amount and frequency of intake of soft drinks and juices. WHO recommends that the Ministries of Health should ensure that the mechanisms for intersectorial collaboration are strengthened. Strategies include taxation and pricing, food labeling, school lunch policies and nutrition programs. This WHO Programme is elaborated for all countries of the World. The Regional Offices of WHO play an important role in the improvement of oral health within risk factor approach in disease prevention and health promotion. Therefore, the Global Oral Health Programme will help to achieve greater equity in oral health. But to evaluate the Global Oral Health Programme, we need suitable and validated indicators and indexes [52]. There is currently only one global oral health index to measure oral health. It is the Decayed, Missing, Filled Teeth (DMFT) index. According to the WHO Oral Health Data 
Bank in the year 2000 from 184 countries, $68 \%$ had a DMFT index less than 3 [52]. Up to now, there is only the DMFT index for 12-year-old children in the Health for all 21 Database (www.euro.who.int: HFA-21 DB, downloaded June 13, 2007).

The European Commission launched from 2003 to 2005 the EU-Project: European Global Oral Health Indicators coordinated by the Université Claude Bernard de Lyon, to support European Member States in their efforts to reduce the toll of morbidity, disability related to oral health diseases and especially [18]:

a) To identify indicators of oral health, of critical oral health care, its quality of care and of essential health resources

b) To strengthen the ability at the local, national and regional levels to measure, compare and determine the effects of oral health services and use of resources

c) To identify indicators of oral health (problems, determinants and risk factors related to lifestyle) of critical oral health care

d) To identify the types of data generation and management problems within the Health Information System

e) To identify principles for guiding the selection and use of oral health indicators

f) To identify a set of core indicators for oral health

g) To review the recent oral health-indicator selection efforts

In total, 66 indicators are proposed, but no indicator for dental erosion is considered [18]. Therefore up to now, the only international reference in the area of oral health is the DMFT index. The European Commission assesses the quality of oral health data as inadequate for planning, implementation, management and evaluation. The number of internationally recommended indicators complicates the national selection of indicators and the comparability of indicators and indexes [18]. The statements of the European Global Oral Health Indicators Report coincide with the experience in the field of development and using of different erosion indexes. Therefore, it would be necessary to strengthen the international alliance of dentists, epidemiologists, statisticians and other scientists and politicians, to develop an adequate oral health indicators set, i.e. as a subset or user-window of the ECHI-Database (European Community Health Indicators-Database) and within the Oral Databank of the WHO and to develop an internationally agreed and accepted erosion index.

Societies around the world today are increasingly witnessing significant changes in diets and lifestyles which have an impact on oral health. Dental erosion seems to be a growing problem, and in some countries, an increase in erosion of teeth is associated with a higher consumption of beverages containing acids [52]. Within a revision of the WHO Oral Health Surveys Basic Methods, new oral disease patterns, e.g. dental erosion, have to be taken into account [52]. The WHO urges the development of methodologies and approaches for evaluating the effectiveness of community oral health programs focusing on health promotion and disease prevention. Additionally, the formulation of new WHO oral health goals up to the year 2020 have been initiated [52].

Most indexes use different clinical examination standards for measuring tooth erosion especially in preschool- and schoolchildren [25]. Such examination standards could be:

-The full mouth or partial recording

-The examination of primary and/or of only permanent teeth

-The examination of all surfaces or partial recording of surfaces

On this basis, a lot of indexes for the clinical diagnosis of erosive tooth wear have been proposed, which are more or less modifications of combinations of the index published by Eccles [17] or Smith and Knight [48]. The most cited examples of Erosion Indexes developed during the last 20 years are [adopted from 20]:

-The Smith and Knight Tooth Wear Index (TWI) (1984) [48]

-The Eccle's Index (1979) [17]

-UK National Survey of Children's Dental Health Index (1999/2003) [35]

-Erosion Index according to Lussi (1996) [33]

-Modified scoring system of Linkosalo and Markkanen (1985) [19]

-Aine Index 1993 [1]

-The Larsen and Westergaard Index (2000) [30]

-The O'Sullivan Index (2000) [39]

Recently, the question has arisen how reliable and valid current diagnostic criteria and data on erosion are. The indexes developed and used during the last 20 years are not comparable; a gold standard does not exist, and validation studies have not had the effect of identifying an index that could be used as a standard for assessing tooth erosion. The following questions should be answered to advance the definition and assessment of tooth erosion:

-Which erosion indexes are mostly used in the scientific literature?

-Which quality criteria should indexes possess?

-What differences exist between individual- and population-based erosion indexes? 
Finally in the discussion, we will debate whether it is possible to involve erosion indexes into Health Indicator Sets and into International Classification of Diseases (ICD; e.g. ECHI, HFA21, country databases on oral Health, ICD-11).

\section{Erosion index in the scientific literature}

A literature analysis with regard to erosion indexes for the period 2000-2006 was carried out. For this purpose, a Medline research was done considering mesh terms and keywords "tooth erosion" and "dental erosion" in connection with "index". All human studies published in English found by this search strategy were analyzed for the erosion indexes used. In the literature analyses, a total of 1,380 articles were found with regard to the mesh terms and keywords "tooth erosion" or "dental erosion". Approximately 326,112 articles were found with regard to the mesh term and keyword "index". The conjunction of both revealed a total of 91 articles. From these articles, 40 were excluded as they were published before the year 2000, three were excluded because they were not English-language publications, eight studies were not included as no humans were involved, and one review was excluded. In total, 40 publications were considered in the literature review. Of 22 publications, 14 cross sectional studies were found in children, and 18 publications/cross sectional studies were found in adults. The erosion indexes used are presented in Tables 1 and 2 for children and adults, respectively. In children, the UK children dental health survey index [35] was used in four studies, the O'Sullivan Index [39] in three, an index developed in 1993 by Aine et al. [1] was used in two studies, and the Smith and Knight TWI [48] in one study. However, in most studies $(n=4)$, differently designed erosion indexes were considered. In adults, the Smith and Knight TWI [48] was used in most studies $(n=10)$ followed by the Eccle's Index [17] $(n=2)$, Lussi Index [33] $(n=1)$, UK adult dental health survey index $(n=1)$ and an index developed by Schweizer-Hirt et al. 1978 [47]. In one study, the method for estimating the tooth erosion was not mentioned.

\section{Quality criteria of indexes for measuring tooth erosion}

Instruments or indexes for measuring a construct of interestquality of life or intelligence, mental health status or tooth erosion-should possess certain quality characteristics.

Table 1 Used dental erosion indexes in human cross-sectional studies for children found in Medline from the years 2000-2006

\begin{tabular}{|c|c|c|c|c|}
\hline Aim of the study & $n$ & Study population & Referred index & Source \\
\hline Erosive tooth wear & 463 & $\begin{array}{l}\text { Kindergarten, 3- to 5-year-old } \\
\text { children }\end{array}$ & O'Sullivan Index & Wiegand et al. [54] \\
\hline Dental erosion & 153 & 11-year-olds & O'Sullivan Index & Caglar et al. [10] \\
\hline Prevalence of dental erosion & 499 & School setting; 12-year-old children & O’Sullivan Index & Peres et al. [43] \\
\hline Prevalence of dental erosion & 1,949 & $\begin{array}{l}\text { Preschool children; } 3 \text { - to } 5 \text {-year-old } \\
\text { children }\end{array}$ & $\begin{array}{l}\text { UK Children dental health } \\
\text { survey index }\end{array}$ & Luo et al. [32] \\
\hline Prevalence of dental erosion & 832 & 6- and 12-year-old school children & Own erosion index & Truin et al. [50] \\
\hline SES and ethnicity and oral health & 1,753 & $\begin{array}{l}\text { Random sample of } 12 \text { - and } \\
14 \text {-year-old children }\end{array}$ & $\begin{array}{l}\text { UK Children dental health } \\
\text { survey index }\end{array}$ & $\begin{array}{l}\text { Dugmore and Rock } \\
\text { [16] }\end{array}$ \\
\hline $\begin{array}{l}\text { Accuracy and reproducibility of school } \\
\text { dental screening }\end{array}$ & 570 & Primary-school children & New index was developed & $\begin{array}{l}\text { Hetherington and } \\
\text { White [24] }\end{array}$ \\
\hline $\begin{array}{l}\text { Prevalence of and risk factors for dental } \\
\text { erosion }\end{array}$ & 95 & Children and adults & Own erosion index & Johansson et al. [28] \\
\hline Oral health and gastro-oesophageal reflux & 52 & $\begin{array}{l}\text { Children with gastro-oesophageal } \\
\text { reflux disease }\end{array}$ & Aine Index & Linnett et al. [31] \\
\hline $\begin{array}{l}\text { Asthma and dental erosion } \\
\text { Prevalence of dental erosion }\end{array}$ & 418 & $\begin{array}{l}\text { Random Sample of 14-year-old } \\
\text { children }\end{array}$ & Smith and Knight TWI & Al-Dlaigan et al. [2] \\
\hline Oral health and gastro-oesophageal reflux & 37 & $\begin{array}{l}\text { Children with gastro-oesophageal } \\
\text { reflux disease }\end{array}$ & Aine Index & Dahshan et al. [15] \\
\hline Prevalence of dental erosions & 987 & $\begin{array}{l}\text { Preschool children, 2- to 5-year-old } \\
\text { children }\end{array}$ & $\begin{array}{l}\text { UK Children dental health } \\
\text { survey index }\end{array}$ & Al-Malik et al. [4] \\
\hline Oral health of children with clefts & 91 & $4-, 8-$, and 12 -year-old children & $\begin{array}{l}\text { UK Children dental health } \\
\text { survey index }\end{array}$ & $\begin{array}{l}\text { Chapple and Nunn } \\
\text { [11] }\end{array}$ \\
\hline Dental erosion and consumption of oranges & 1,010 & 12-year-old children & Own erosion index & Künzel et al. [29] \\
\hline
\end{tabular}


Table 2 Used dental erosion indexes in human cross-sectional studies for adults found in Medline from the years 2000-2006

\begin{tabular}{|c|c|c|c|c|}
\hline Aim of the study & $n$ & Study population & Refered index & Source \\
\hline Tooth survey (surface?) check! loss & 155 & Patients attending a dental hospital & $\begin{array}{l}\text { UK Adult dental health survey } \\
\text { index }\end{array}$ & Rafeek et al. [44] \\
\hline $\begin{array}{l}\text { Tooth wear among psychiatric } \\
\text { patients }\end{array}$ & 143 & Psychiatric patients & Smith and Knight TWI & Al-Hiyasat et al. [3] \\
\hline Tooth wear in elderly & 690 & Local survey, elderly & Eccles Index & Taiwo et al. [49] \\
\hline Tooth surface in winemakers & 36 & Winemakers & Schweizer-Hirt et al. 1978 & Chikte et al. [12] \\
\hline Workplace and dental erosion & 20 & Silicon workers & Own erosion index & Johansson et al. [27] \\
\hline Oral and dental health & 34 & Inpatients in treatment of alcohol disorders & No information given & Araujo et al. [6] \\
\hline $\begin{array}{l}\text { Dental erosion and gastro- } \\
\text { oesophageal reflux }\end{array}$ & $?$ & $\begin{array}{l}\text { Patients with gastro-oesophageal reflux } \\
\text { disease }\end{array}$ & Smith and Knight TWI & Moazzez et al. [36] \\
\hline Prevalence of dental erosion & 18,555 & Permanent dentition & Smith and Knight TWI & Borcic et al. [9] \\
\hline $\begin{array}{l}\text { Dental erosion and gastro- } \\
\text { oesophageal reflux }\end{array}$ & 253 & $\begin{array}{l}\text { Patients with gastro-oesophageal reflux } \\
\text { disease }\end{array}$ & Eccles Index & Munoz et al. [37] \\
\hline Monitoring of tooth wear & 500 & $\begin{array}{l}\text { Patients referred for a variety of restorative } \\
\text { procecdures }\end{array}$ & Smith and Knight TWI & Bartlett [7] \\
\hline Risk factors of tooth wear & 506 & Patients attending a dental hospital & Smith and Knight TWI & $\begin{array}{l}\text { Chuajedong et al. } \\
\text { [13] }\end{array}$ \\
\hline Sport drinks and dental erosion & 304 & Athletes & Lussi Index & Mathew et al. [34] \\
\hline Prevalence of tooth wear & 126 & Patients attending a dental hospital & Smith and Knight TWI & $\begin{array}{l}\text { Oginni and Olusile } \\
\text { [41] }\end{array}$ \\
\hline $\begin{array}{l}\text { Recreational drug and tooth surface } \\
\text { loss }\end{array}$ & 13 & Undergraduate students & Smith and Knight TWI & Nixon et al. [38] \\
\hline Risk factors for dental erosion & 10 & Male military Saudi inductees & Own erosion index & Johansson et al. [28] \\
\hline Oral health status of workers & 68 & Workers exposed to acid fumes & Smith and Knight TWI & Amin et al. [5] \\
\hline Methamphetamine and tooth wear & 43 & Methamphetamine users & Smith and Knight TWI & $\begin{array}{l}\text { Richards and Brofeldt } \\
\text { [45] }\end{array}$ \\
\hline $\begin{array}{l}\text { Dental erosion and gastro- } \\
\text { oesophageal reflux }\end{array}$ & 20 & $\begin{array}{l}\text { Patients with gastro-oesophageal reflux } \\
\text { disease }\end{array}$ & Smith and Knight TWI & $\begin{array}{l}\text { Gregory-Head et al. } \\
\text { [21] }\end{array}$ \\
\hline
\end{tabular}

Otherwise, the scientific value of the obtained results is questionable [8]. Important quality characteristics are validity and reliability as well as sensitivity and specificity, which will be explained in the following paragraphs.

The validity of an instrument indicates to what extent it measures what it is supposed to measure. There are different - partly overlapping - types of validity which emphasize different aspects [42]. The most important types are content, construct, and criterion validity which will be explained in the following paragraphs.

Content validity describes whether all aspects, which are relevant to grasp the construct of interest, have been considered adequately. For example, a test that is supposed to measure the ability to calculate should not be restricted only to addition and subtraction but include all basic arithmetic operations. In our context, e. g. the erosion of surfaces of all teeth has to be considered, not only the erosion of incisors. The extent to which an instrument possesses content validity cannot be determined numerically. It is solely based upon the subjective meaning of established experts [8, 23]. Therefore, a major step in developing a new instrument is a thorough discussion of which aspects should be included.
The optimal method to validate a newly developed instrument is the comparison with a so-called gold standard, which measures the same construct. A gold standard is "the method, procedure or measurement that is widely accepted as being the best available" [46]. The socalled criterion validity is high if the results of the new instrument and the gold standard are highly correlated. For example, a thermometer might serve as a gold standard for self-reported temperature [23].

However, because a gold standard is seldom available, construct validity is of major importance [8]. Construct validity is subdivided into convergent and discriminant validity. There is convergent validity if the results obtained by the new instrument are correlated with the results of an established instruments that measures similar aspects. If, for example, results of a new instrument for measuring physical health are correlated with the results of an established instrument which measures activity of daily living, convergent validity is indicated [8]. Or in our context: if the results of a tooth-wear index is correlated with tooth-erosion index, convergent validity is indicated. On the other hand, an instrument possesses discriminant validity if the results of this instrument are not too highly 
correlated with the results of an established instrument that measures a different construct. For example, results of an instrument for measuring mental health should not be too highly correlated with an instrument for measuring physical function [23]. With regard to teeth, a high correlation between tooth erosion and wedge-shaped defects might indicate insufficient discriminant validity. Both convergent and discriminant validity have to be given for a complete confirmation of construct validity.

The reliability of an instrument indicates how precise it is able to measure, independent of whether it really measures what it is supposed to (this is a question of validity) [42]. There are different aspects of reliability. For our purposes, inter-examiner reliability and intra-examiner reliability are important.

Inter-examiner reliability can be determined if two or more dentists (the "examiner") assess dental erosion of a number of patients independently of each other [14]. Roughly spoken, the more often the examiners agree in their assessment, the higher the inter-examiner reliability. Intra-examiner reliability or test-retest reliability can be determined if each dentist rates dental erosion of a group of patients twice [23]. The period of time between the two assessments should be fairly long, otherwise the examiners may be overly consistent because they remember their former ratings. On the other hand, if the time interval between the two assessments is too long, changes in the erosion status might bias the reliability estimates. The more often the assessments at the two points in time concerning each examiner are identical, the higher the intra-examiner reliability. A widespread index to calculate the degree of agreement is Cohen's Kappa [14], which "is now fairly well disseminated as one of the standard summary statistics used in the medical literature" [22]. The calculation of Kappa is based on the percentage of agreement which is adjusted for agreement expected by chance.

The sensitivity of an instrument indicates its ability to detect-in our case-dental erosion. In contrast, an instrument with high specificity is able to indicate no dental erosion if dental erosion is not present. Both assessment of sensitivity and specificity require the comparison with a gold standard. Comparing a new instrument that is supposed to detect dental erosion with an instrument that is known to be able to detect dental erosion, i.e. a goldstandard instrument, can yield one of the four following outcomes: (1) dental erosion is indicated by the new instrument if there is in fact dental erosion (correct positive), (2) dental erosion is indicated if there is no dental erosion (false positive), (3) dental erosion is not indicated if there is dental erosion (false negative) and (4) dental erosion is not indicated if there is no dental erosion (correct negative). The degree of sensitivity is calculated by dividing the frequency of correct positive results by the sum of correct positive and false negative results, while the degree of specificity is determined by dividing the frequency of correct negative results by the sum of correct negative and false positive results [46].

\section{Individual versus population-based erosion indexes}

An individual-based index should fulfill other criteria than a population-based index. The first should allow assessment of the full truth of the construct "tooth erosion". Therefore, a very good individual-based erosion index should nearly be a gold-standard instrument. Using a population-based erosion index, the individual assessment should take less time to allow an assessment in big population samples. Therefore, for practical reasons, a population-based erosion index is often a short form of an individual-based index. However, a good population-based erosion index should possess very high validity as well as high reliability.

\section{Discussion}

There is no common sense in the usage of the abovementioned erosion indexes. A wide range of different forms and indexes was used in the last 6 years. Therefore, comparability between different studies was not given, and meta-analyses were not possible. If anything, it can be stated that for adults, the Smith and Knight TWI [48] has been widely used in most Medline-cited cross-sectional studies. For children, there is no index that is most used. However, the literature analysis is limited. Only one search strategy was used. Some articles which do not use the mentioned key words or mesh headings might not be included in the analysis. However, the results presented help to get a first view on the different indexes on tooth erosion cited in the last 6 years.

In all these indexes, the criteria to record the grading for erosion differed [26]. Most of the indexes used are based on the clinical severity of erosion, focusing on accessible teeth but not all [29]. For example, the structure of the Smith and Knight TWI is shown in Table 3. However, this index is made for scoring tooth wear in general irrespective of its predominant aetiology. It is only a system for quantifying and grading the amount of tissue loss but does not include diagnostic criteria for erosion. The UK National Survey of Children's Dental Health Index was a modified version of the Smith and Knight TWI assessing only buccal or palatal surfaces of maxillary incisors and added erosion criteria. However, while using the first index, the conclusion was drawn that the figures might not be completely accurate [40]. The next version focused on erosion of the palatal surface of at least one maxillary anterior tooth with the 
Table 3 Smith and Knight Tooth Wear Index [48]

\begin{tabular}{lll}
\hline Score & Surface & Criterion \\
\hline 0 & $\mathrm{~B} / \mathrm{L} / \mathrm{O} / \mathrm{I} / \mathrm{C}$ & No loss of surface characteristic, no loss of contour \\
1 & $\mathrm{~B} / \mathrm{L} / \mathrm{O} / \mathrm{I} / \mathrm{C}$ & Loss of enamel surface characteristics, minimal loss of contour \\
2 & $\mathrm{~B} / \mathrm{L} / \mathrm{O}$ & Loss of enamel exposing dentine for less than one third of the surface \\
& $\mathrm{I}$ & Loss of enamel just exposing dentine \\
$\mathrm{C}$ & Defect less then $1 \mathrm{~mm}$ deep \\
$\mathrm{B} / \mathrm{L} / \mathrm{O}$ & Loss of enamel exposing dentine for more than one third of surface \\
& $\mathrm{I}$ & Loss of enamel and substantial loss of dentine not exposing secondary dentine or pulp \\
& $\mathrm{C}$ & Defect 1-2 mm deep \\
& $\mathrm{B} / \mathrm{L} / \mathrm{O}$ & Complete loss of enamel, or pulp exposure, or exposure of secondary dentine \\
$\mathrm{I}$ & Pulp exposure or exposure of secondary dentine \\
$\mathrm{C}$ & Defect more than 2 mm deep, or pulp exposure, or exposure of secondary dentine \\
\hline
\end{tabular}

$B$ Buccal or labial, $L$ lingual or palatal, $O$ occlusal, $I$ incisal, $C$ cervical

majority of surfaces having dentin involvement [29]. To date, literature assessing the prevalence of erosion has been published from different countries. Erosion was recorded using various indexes. In addition, selection criteria of study populations, sampling techniques and considered age groups differed. The prevalence of dental erosion of different studies is therefore difficult and nearly impossible to compare [29].

A good index is characterized by a conducted validation study. For those indexes for which a validation study has not been conducted so far, that should be made up to check whether they possess the quality criteria as described above. In a validation study, it is not only the validity of an index that is examined but also aspects of reliability as well. Intraexaminer and inter-examiner reliability should be checked. That is done quite easily as described in "Quality criteria of indexes for measuring tooth erosion". At the beginning of the study, it has to be considered how many patients and how many examiners respectively have to be involved. This is because the number of patients and examiners should be as small as possible for practical and economic reasons. On the other hand, the number of patients and examiners has to be sufficiently high because otherwise a certain degree of reliability, which actually exists, might be overlooked. Therefore, solid sample-size calculations should be conducted with the help of an experienced statistician.

So far, there is no consensus concerning a gold-standard instrument. However, a gold standard is important for comparison. Otherwise, criterion validity cannot be checked. If one attempts to develop a gold-standard instrument, the first step would be a thorough discussion of which aspects of the construct "tooth erosion" have to be included. This should be conducted by established experts to ensure content validity. When the instrument is constructed, inter-examiner reliability and intra-examiner reliability can be examined as described above. However, this should be done not only in a national but in an international context.
A gold-standard instrument would explain the full truth of the construct "tooth erosion". Nevertheless, the measurement procedure in general takes a long time. It is not possible to deal with such a comprehensive assessment instrument in a population-based study design. Therefore, more simple assessment instruments should be available. These assessment instruments should fulfill the following qualifications: (a) a validation study should be available where all quality criteria of the assessment instrument were tested and (b) the instrument should be used in other scientific studies, too. If the population-based short version of an assessment instrument and the gold-standard instrument are measuring the same construct, and when both conditions are fulfilled, calibration studies might be possible. Calibration refers to a process in which values from one method are quantitatively related to values from a superior, gold-standard method. The aim of such an analysis is to ensure that the measurement uncertainty is known and is consistent with the required measurement capability. In a so-called calibration study, known data on the observed relationship between an independent variable of the population-based short version of the assessment

Table 4 Code description for K03.2-Erosion of teeth (ICD 10 code) [51]

\begin{tabular}{ll}
\hline $\begin{array}{l}\text { ICD 10 } \\
\text { code }\end{array}$ & Description \\
\hline K03.2 & $\begin{array}{l}\text { Erosion of teeth } \\
\text { K03.20 }\end{array}$ \\
K03.21 & $\begin{array}{l}\text { Erosion of teeth due to persistent regurgitating or } \\
\text { vomiting }\end{array}$ \\
K03.22 & Erosion of teeth due to diet \\
K03.23 & Erosion of teeth due to drugs and medicaments \\
K03.24 & Idiopathic erosion of teeth \\
K03.28 & Other specified erosion of teeth \\
K03.29 & Erosion of teeth, unspecified
\end{tabular}


instrument and the dependent variable of the gold-standard instrument are used to make estimates of other "true" values of the independent variable from new observations of the gold standard.

One of the prospective targets ought to be the inclusion of indexes on dental health prevention especially of an internationally agreed "erosion index" into the existing Health Indicator Sets. These would be the Health for All Database of the WHO (HFA21), The European Community Health Indicator Set (ECHI), Country Databases on Oral Health and the inclusion of Dental Erosion into the International Classification of Diseases and Health-Related Problems.

In April 2007, the World Health Organization announced plans to revise the ICD-10, in other words, to prepare for ICD-11. Within the actual ICD-10, there exists two codes for Dental Diseases: "K02" for Caries and "K03" for "Other diseases of hard tissues of teeth" including with "K03.2-Erosion of teeth." On the four-digit level, we find the following different diagnoses presented in Table 4.

The Updating and Revision Committee proposes major changes like addition of new codes or deletion of codes and developed submission guidelines. Therefore, it would be possible to check critically if the codes for dentistry within the Application of the International Classification of Diseases to Dentistry and Stomatology are adequate to future developments or have to be replaced or completed [53].

\section{Conclusion}

Further efforts have to be made in the development of an internationally agreed index which is able to assess dental erosion with as much reliability and validity as possible. Current recommendations of the WHO and the European Union and health task forces within countries and Dental Associations should be used to develop and to discuss the concept of tooth erosion and the development of a unified erosion index.

Acknowledgements The authors would like to express their thankfulness for the competent advice on the actual situation in the field of the development of Erosion Indexes to Prof. Dr. Carolina Ganss, Department of Conservative and Preventive Dentistry, Dental Clinic Justus Liebig University Giessen, Germany.

\section{References}

1. Aine L, Baer M, Maki M (1993) Dental erosions caused by gastro-esophageal reflux disease in children. J Dent Child 60:765769
2. Al-Dlaigan YH, Shaw L, Smith AJ (2002) Is there a relationship between asthma and dental erosion? A case control study. Int J Paediatr Dent 12:189-200

3. Al-Hiyasat AS, Khasawneh SF, Khader YS (2006) Tooth wear among psychiatric patients: prevalence, distribution, and associated factors. Int J Prosthodont 19:403-9

4. Al-Malik MI, Holt RD, Bedi R (2002) Erosion, caries and rampant caries in preschool children in Jeddah, Saudi Arabia. Community Dent Oral Epidemiol 30:16-23

5. Amin WM, Al-Omoush SA, Hattab FN (2001) Oral health status of workers exposed to acid fumes in phosphate and battery industries in Jordan. Int Dent J 51:169-74

6. Araujo MW, Dermen K, Connors G, Ciancio S (2004) Oral and dental health among inpatients in treatment for alcohol use disorders: a pilot study. J Int Acad Periodontol 6:125-30

7. Bartlett DW (2003) Retrospective long term monitoring of tooth wear using study models. Br Dent J 194:211-213

8. Berzon RA (1998) Understanding and using health-related quality of life instruments within clinical research studies. In: Staquet MJ, Hays RD, Fayers PM (eds) Quality of life assessment in clinical trials-methods and practice. Oxford University Press, Oxford, New York, pp 3-15

9. Borcic J, Anic I, Urek MM, Ferreri S (2004) The prevalence of non-carious cervical lesions in permanent dentition. J Oral Rehabil 31:117-123

10. Caglar E, Kargul B, Tanboga I, Lussi A (2005) Dental erosion among children in an Istanbul public school. J Dent Child 72:5-9

11. Chapple JR, Nunn JH (2001) The oral health of children with clefts of the lip, palate, or both. Cleft Palate Craniofac J 38:525528

12. Chikte UM, Naidoo S, Kolze TJ, Grobler SR (2005) Patterns of tooth surface loss among winemakers. SADJ 60:370-374

13. Chuajedong P, Kedjarune-Leggat U, Kertpon V, Chongsuvivatwong V, Benjakul P (2002) Associated factors of tooth wear in southern Thailand. J Oral Rehabil 29:997-1002

14. Cohen J (1960) A coefficient of agreement for nominal scales. Edu Psychol Meas 20:37-46

15. Dahshan A, Patel H, Delaney J, Wuerth A, Thomas R, Tolia V (2002) Gastro-esophageal reflux disease and dental erosion in children. J Pediatr 140:474-478

16. Dugmore CR, Rock WP (2005) The effect of socio-economic status and ethnicity on the comparative oral health of Asian and White Caucasian 12-year-old children. Community Dent Health 22:162-169

17. Eccles JD (1979) Dental erosion of nonindustrial origin. A clinical survey and classification. J Prosthet Dent 42:649-653

18. European Commission/Health and Consumer Protection Directorate General (2005) Health Surveillance in Europe. European Global Oral Health Indicators Development Project. SPC 2002472. Final Report 2003-2005

19. Ganss C, Klimek J, Giese K (2001) Dental erosion in children and adolescents - a cross-sectional and longitudinal investigation using study models. Community Dent Oral Epidemiol 29:264-271

20. Ganss C, Lussi A (2006) Diagnosis of erosive tooth wear. In: Lussi A (ed) Dental Erosion. Karger, Basel, pp 32-43

21. Gregory-Head BL, Curtis DA, Kim L, Cello J (2000) Evaluation of dental erosion in patients with gastroesophageal reflux disease. J Prosthet Dent 83:675-680

22. Guggenmoos-Holzmann I (1993) How reliable are chancecorrected measures of agreement? Stat Med 12:2191-2205

23. Hays RD, Anderson RT, Revicki D (1998) Assessing reliability and validity of measurement in clinical trials. In: Staquet MJ, Hays RD, Fayers PM (eds) Quality of life assessment in clinical trials - methods and practice. Oxford University Press, Oxford, New York, pp 169-182 
24. Hetherington I, White DA (2004) The diagnostic accuracy and reproducibility of school dental screening using an index of treatment need. Community Dent Health 21:170-174

25. Jaeggi T, Lussi A (2006) Prevalence, incidence and distribution of erosion. In: Lussi A (ed) Dental Erosion. Karger, Basel, pp 44-65

26. Johansson AK (2002) On dental erosion and associated factors. Swed Dent J Suppl 156:1-77

27. Johansson AK, Johansson A, Stan V, Ohlson CG (2005) Silicone sealers, acetic acid vapors and dental erosion: a work-related risk? Swed Dent J 29:61-69

28. Johansson AK, Lingstrom P, Birkhed D (2002) Comparison of factors potentially related to the occurrence of dental erosion in high- and low-erosion groups. Eur J Oral Sci 110:204-11

29. Künzel W, Cruz MS, Fischer T (2000) Dental erosion in Cuban children associated with excessive consumption of oranges. Eur J Oral Sci 108:104-109

30. Larsen IB, Westergaard J, Stoltze K, Larsen AI, Gyntelberg F, Holmstrup P (2000) A clinical index for evaluating and monitoring dental erosion. Community Dent Oral Epidemiol 28:211-217

31. Linnett V, Seow WK, Connor F, Shepherd R (2002) Oral health of children with gastro-esophageal reflux disease: a controlled study. Aust Dent J 47:156-162

32. Luo Y, Zeng XJ, Du MQ, Bedi R (2005) The prevalence of dental erosion in preschool children in China. J Dent 33:115-121

33. Lussi A (1996) Dental erosion: clinical diagnosis and case history taking. Eur J Oral Sci 104:191-198

34. Mathew T, Casamassimo PS, Hayes JR (2002) Relationship between sports drinks and dental erosion in 304 university athletes in Columbus, Ohio, USA. Caries Res 36:281-287

35. Milosevic A, Bardsley PF, Taylor S (2004) Epidemiological studies to tooth wear and dental erosion in 14-year old children in North West England. Part 2: The association of diet and habits. Br Dent J 197:479-483

36. Moazzez R, Bartlett D, Anggiansah A (2004) Dental erosion, gastro-oesophageal reflux disease and saliva: how are they related? J Dent 32:489-494

37. Munoz JV, Herreros B, Sanchiz V, Amoros C, Hernandez V, Pascual I, Mora F, Minguez M, Bagan JV, Benages A (2003) Dental and periodontal lesions in patients with gastro-oesophageal reflux disease. Dig Liver Dis 35:461-467

38. Nixon PJ, Youngson CC, Beese A (2002) Tooth surface loss: does recreational drug use contribute? Clin Oral Investig 6:128-130

39. O'Sullivan EA (2000) A new index for the measurement of erosion in children. Eur J Paediatr Dent 2:69-74
40. O'Brien M (1994) Children's Dental Health in the United Kingdom 1993. London: Office of Population Censuses and Surveys. Her Majesty's Stationary Office, London 1993

41. Oginni O, Olusile AO (2002) The prevalence, aetiology and clinical appearance of tooth wear: the Nigerian experience. Int Dent J 52:268-272

42. Osoba D (1998) Guidelines for measuring health-related quality of life in clinical trials. In: Staquet MJ, Hays RD, Fayers PM (eds) Quality of life assessment in clinical trials - methods and practice. Oxford University Press, Oxford, New York, pp 19-35

43. Peres KG, Armenio MF, Peres MA, Traebert J, De Lacerda JT (2005) Dental erosion in 12-year-old schoolchildren: A crosssectional study in Southern Brazil. Int J Paediatr Dent 15:249-255

44. Rafeek RN, Marchan S, Eder A, Smith WAJ (2006) Tooth surface loss in adult subjects attending a university dental clinic in Trinidad. Int Dent J 56:181-186

45. Richards JR, Brofeldt BT (2000) Patterns of tooth wear associated with methamphetamine use. J Periodontol 71:1371-1374

46. Schwarzer G, Türp JC, Antes G (2002) Die Vierfeldertafel (in Diagnosestudien): Sensitivität und Spezifität. Dtsch Zahnärztl Z $57: 333-334$

47. Schweizer-Hirt CM, Schait A, Schmid R, Imfeld T, Lutz F, Mühlmann HR (1978) Erosion und Abrasion des Schmelzes. Eine experimentelle Studie. Schweiz. Monatsschr Zahnheilkd 88:497-529

48. Smith BGN, Knight JK (1984) An index for measuring the wear of teeth. Br Dent J 157:16-19

49. Taiwo JO, Ogunyinka A, Onyeaso CO, Dosumu OO (2005) Tooth wear in the elderly population in south east local government area in Ibadan, Nigeria. Odontostomatol Trop 28:9-14

50. Truin GJ, van Rijkom HM, Mulder J, van't Hof MA (2005) Caries trends 1996-2002 among 6- and 12-year-old children and erosive wear prevalence among 12-year-old children in The Hague. Caries Res 39:2-8

51. WHO World Health Organization Geneva (1995) Application of the international classification of diseases to dentistry and stomatology. ICD-DA. Third Edition. World Health Organization, Geneva

52. WHO (2003) The World Health Report 2003. Oral Health Programme. WHO, Geneva NMH/NPH/ORH/03.2

53. WHO Updating \& Revision Committee: www.who.int/classifications/ committees/URC.pdf: downloaded: June 13, 2007

54. Wiegand A, Muller J, Werner C, Attin T (2006) Prevalence of erosive tooth wear and associated risk factors in 2-7-year-old German kindergarten children. Oral Dis 12:117-124 